\title{
Surgical decortication as the first-line treatment for pleural empyema
}

\author{
Jung Ar Shin, MD, ${ }^{a}$ Yoon Soo Chang, MD, PhD, ${ }^{a}$ Tae Hoon Kim, MD, PhD, ${ }^{b}$ Seok Jin Haam, MD, ${ }^{c}$ \\ Hyung Jung Kim, MD, PhD, ${ }^{a}$ Chul Min Ahn, MD, PhD, ${ }^{a}$ and Min Kwang Byun, $\mathrm{MD}^{\mathrm{a}}$
}

Objective: The study objective was to evaluate the clinical outcomes of surgical decortication as the first line of treatment for pleural empyema.

\begin{abstract}
Methods: We analyzed the medical records of 111 patients who presented with empyema and were treated with simple drainage or surgical decortication as the first line of treatment at Gangnam Severance Hospital, a tertiary referral medical center in Seoul, Korea.

Results: Of 111 patients with empyema, 27 underwent surgical decortication as the first intervention. Surgical decortication showed a better treatment success rate in all study subjects $(96.3 \%, 26 / 27$ patients) compared with simple drainage $(58.3 \%, 49 / 84$ patients; $P<.0001$ for method comparison). After propensity-scored matching, decortication resulted in a better outcome $(95.0 \%, 19 / 20$ patients) versus drainage $(56.7 \%, 17 / 30$ patients; $P=.003$ ). Surgical decortication as the first line of treatment for empyema was the best predictor of treatment success after adjustment for compounding factors (odds ratio, 14.529; 95\% confidence interval, 1.715-123.074; $P=.014)$.
\end{abstract}

Conclusions: The first treatment choice for pleural empyema is a critical determinant of ultimate therapeutic success. After adjusting for confounding variables, surgical decortication is the optimal first treatment choice for advanced empyema. (J Thorac Cardiovasc Surg 2013;145:933-9)

Supplemental material is available online.

Pleural empyema is defined as the presence of purulent fluid within the pleural space. Most empyemas occur in association with pneumonia, although empyema has no relation with pneumonia in approximately one third of patients. ${ }^{1}$ Empyema due to tuberculosis (TB) is increasingly prevalent in TB-endemic countries. ${ }^{2,3}$ Empyema often causes substantial morbidity and mortality. ${ }^{4}$ In 1962 , the American Thoracic Society ${ }^{5}$ described the 3 phases of empyema as exudative (stage I), fibrinopurulent (stage II), and organizing (stage III). In the initial exudative stage, closed chest drainage and appropriate antibiotic administration can comprise effective treatment. Antimicrobial therapy successfully resolves small uniloculated empyema with an $80 \%$ success rate. ${ }^{6}$ However, in the later fibrinopurulent and organizing stages, antibiotics are not effective because of

\footnotetext{
From the Departments of Internal Medicine, ${ }^{\mathrm{a}}$ Radiology, ${ }^{\mathrm{b}}$ and Thoracic and Cardiovascular Surgery, ${ }^{\mathrm{c}}$ Gangnam Severance Hospital, Yonsei University College of Medicine, Yonsei University Health System, Seoul, Korea.

Disclosures: Authors have nothing to disclose with regard to commercial support.

Received for publication March 5, 2012; revisions received June 13, 2012; accepted for publication July 25, 2012; available ahead of print Aug 27, 2012.

Address for reprints: Min Kwang Byun, MD, Department of Internal Medicine, Gangnam Severance Hospital, Yonsei University College of Medicine, Yonsei University Health System, 211 Eonju-ro, Gangnam-gu, Seoul 135-720, Korea (E-mail: littmann@yuhs.ac).

$0022-5223 / \$ 36.00$

Copyright (c) 2013 by The American Association for Thoracic Surgery

http://dx.doi.org/10.1016/j.jtcvs.2012.07.035
}

pleural peel and fluid loculation. If initial noninvasive treatment fails, surgical intervention involving thoracotomy and decortication is an alternative choice. Depending on the surgeon's experience, surgical intervention can be performed using minimally invasive techniques, such as decortication by video-assisted thoracoscopic surgery (VATS), or open thoracotomy. Although the optimal therapeutic approach for empyema remains undetermined, surgery has been shown to be an effective treatment option, especially in multiloculated empyema. On the other hand, the risks of surgery need to be balanced against the expected benefits. The evolutionary stages of pleural empyema are not clearly defined, but rather represent a continuous spectrum of events. Some patients with empyema have enough time to undergo surgical therapy as an alternative choice, despite the failure of attempted medical therapy. Other patients have no time to undergo alternative therapies, because the disease progresses rapidly with concomitant health deterioration, and surgery is the only option. Thus, the first therapeutic choice for empyema should be made deliberately. Empyema management traditionally has been empirical, but recent data favor establishing more specific management guidelines. In this study, we reviewed our clinical experience in treating pleural empyema in both nontuberculous and tuberculous scenarios.

\section{PATIENTS AND METHODS \\ Patient Characteristics}

We retrospectively analyzed the medical records of 111 patients who presented with empyema between January 2008 and July 2011 at Gangnam Severance Hospital, a tertiary referral medical center in Seoul, Korea. The 


$\begin{aligned} & \text { Abbreviations and Acronyms } \\ & \text { ACCP }= \text { American College of Chest } \\ & \text { Physicians } \\ & \text { APACHE II }= \text { Acute Physiology and Chronic } \\ & \text { Health Evaluation II } \\ & \text { BMI } \text { body mass index } \\ & \text { CCI }=\text { Charlson Comorbidity Index } \\ & \text { ECOG }=\text { Eastern Cooperative Oncology } \\ & \text { Group } \\ & \text { TB }=\text { tuberculosis } \\ & \text { VATS }=\text { video-assisted thoracoscopic surgery }\end{aligned}$

study population consisted of patients aged more than 18 years with a diagnosis of empyema. Data regarding clinical profile, initial and final diagnoses, and disease severity were recorded (Table 1). This study was approved by the Institutional Review Board, Gangnam Severance Hospital, Yonsei University College of Medicine (Institutional Review Board No: 3-20110283), and the necessity for written informed consent was waived because this was a retrospective study and patients were anonymized.

\section{Empyema Cause}

Pleural fluid was investigated by microbiological and biochemical methods. Bacterial culture, Gram staining, acid-fast bacilli smears, and Mycobacterium tuberculosis culture were performed on both pleural and sputum samples. Biochemical analysis of pleural fluid included $\mathrm{pH}$, glucose level.

In our study, tuberculous empyemas were analyzed together with nontuberculous bacterial empyemas. Tuberculous pleural effusions are common findings in TB-endemic countries, and tuberculous empyema is associated with high morbidity and mortality unless surgically treated. Patients presenting with pleural empyema should be assessed for tuberculous empyema in TB-endemic countries.

\section{Patient Inclusion Criteria, Disease Definition, and Patient Grouping}

Inclusion criteria were pleural empyema diagnosis and age more than 18 years. Empyema was defined as septations or loculations identified in the pleural space by computed tomography. In addition, empyema was defined as frank pus aspirated from the pleural space or positive Gram stain or culture identification of pathogens in pleural fluid ${ }^{1}$ by microbiological and biochemical methods. Malignant pleural effusions and trauma-related effusions were excluded. Two radiologists reviewed chest computed tomography findings of all patients with suspected empyema individually until diagnostic consensus was attained. We excluded the patients for whom the 2 radiologists failed to reach a consensus. Empyema stage was determined using the American College of Chest Physicians (ACCP) classification of parapneumonic effusion (Table 2). ${ }^{7}$

The surgical group was defined as patients who were treated with surgical decortication, including VATS and open thoracotomy, as the first line of treatment for pleural empyema. The drainage group was defined as patients who were treated with simple drainage (insertion of an $8 \mathrm{~F}$ pigtail catheter or a $32 \mathrm{~F}$ large-bore chest tube).

After the intervention was completed, we evaluated the treatment outcomes with chest computed tomography scan and judged them by comparison with baseline findings. Treatment success was defined as complete evacuation of the infected pleural fluid and restoration of complete lung expansion, with follow-up radiologic examination indicating that no further intervention was needed. Treatment failure was defined as the requirement for additional intervention or as empyema-attributable mortality.

\section{Statistical Analyses}

Data were analyzed with the Statistical Package for the Social Sciences version 18.0 (SPSS Inc, Chicago, Ill) and SAS version 9.2 statistical software (SAS Institute Inc, Cary, NC). All tests were 2-sided. Categoric variables were compared by Fisher exact test and Pearson's chi-square test, as appropriate. Continuous variables were compared with Student $t$ test. The associations of clinical and laboratory parameters with treatment success were analyzed using univariate or multivariate logistic regression modeling. For multivariate analysis, the variables were incorporated into the

TABLE 1. Baseline characteristics of all study subjects

\begin{tabular}{|c|c|c|c|c|}
\hline Variable & Total $(\mathrm{N}=111)$ & Surgery $(n=27)$ & Drainage $(n=84)$ & $P$ value \\
\hline Age, y & $56.1 \pm 20.0$ & $52.0 \pm 13.2$ & $57.4 \pm 21.7$ & .222 \\
\hline Gender, male, $\mathrm{n}(\%)$ & $88(79.3)$ & $22(81.5)$ & $66(78.6)$ & .746 \\
\hline BMI, $\mathrm{kg} / \mathrm{m}^{2}$ & $21.6 \pm 3.7$ & $23.5 \pm 3.2$ & $21.0 \pm 3.7$ & .002 \\
\hline Diabetes, n (\%) & $23(20.7)$ & $8(29.6)$ & $15(17.9)$ & .189 \\
\hline CCI, median (range) & $0(0-6)$ & $0(0-3)$ & $1(0-6)$ & .014 \\
\hline Mean arterial pressure, $\mathrm{mm} \mathrm{Hg}($ mean $\pm \mathrm{SD})$ & $85.9 \pm 18.2$ & $86.9 \pm 13.7$ & $85.6 \pm 19.5$ & .766 \\
\hline ECOG, $\mathrm{n}(\%)$ & & & & $<.001$ \\
\hline 0 & $53(47.7)$ & $23(85.2)$ & $30(35.7)$ & \\
\hline 1 & $22(19.8)$ & $2(7.4)$ & $20(23.8)$ & \\
\hline 2 & $15(13.5)$ & $2(7.4)$ & $13(15.5)$ & \\
\hline 3 & $11(9.9)$ & $0(0.0)$ & $11(13.1)$ & \\
\hline 4 & $10(9.0)$ & $0(0.0)$ & $10(11.9)$ & \\
\hline APACHE II score at diagnosis, median (range) & $7(0-33)$ & $6(0-14)$ & $9(0-33)$ & .013 \\
\hline Diagnosis, n (\%) & & & & .087 \\
\hline Parapneumonic & $73(65.8)$ & $21(77.8)$ & $52(61.9)$ & \\
\hline $\mathrm{TB}$ & $33(29.7)$ & $4(14.8)$ & $29(34.5)$ & \\
\hline Postoperative & $4(3.6)$ & $1(3.7)$ & $3(3.6)$ & \\
\hline Others & $1(0.9)$ & $1(3.7)$ & $0(0.0)$ & \\
\hline Duration of symptoms to admission, $\mathrm{d}$ & $9.6 \pm 12.0$ & $10.3 \pm 9.0$ & $9.3 \pm 12.8$ & .728 \\
\hline Duration of symptoms to treatment, $\mathrm{d}$ & $13.5 \pm 10.1$ & $13.9 \pm 8.9$ & $13.3 \pm 10.4$ & .800 \\
\hline
\end{tabular}

Age, BMI, mean arterial pressure, and days are all presented as mean values \pm SD. BMI, Body mass index; $C C I$, Charlson Comorbidity Index; $S D$, standard deviation; $E C O G$, Eastern Cooperative Oncology Group; APACHE II, Acute Physiology and Chronic Health Evaluation II; TB, tuberculosis. 
TABLE 2. Categorizing risk for poor outcome in empyema and parapneumonic effusion

\begin{tabular}{|c|c|c|c|c|c|c|c|c|c|c|}
\hline \multicolumn{2}{|r|}{ Pleural space anatomy } & \multicolumn{4}{|c|}{ Pleural fluid bacteriology } & \multicolumn{2}{|c|}{ Pleural fluid chemistry } & \multirow{2}{*}{$\frac{\text { Category }}{1}$} & \multirow{2}{*}{$\begin{array}{l}\text { Risk of poor } \\
\text { outcome }\end{array}$} & \multirow{2}{*}{$\frac{\text { Drainage }}{\text { No }}$} \\
\hline $\mathrm{A}_{0}$ & $\begin{array}{l}\text { Minimal, free-flowing effusion } \\
\text { ( }<10 \mathrm{~mm} \text { on lateral decubitus })\end{array}$ & and & $\mathrm{B}_{\mathrm{x}}$ & $\begin{array}{l}\text { Culture and Gram-stain } \\
\text { results unknown }\end{array}$ & and & $\mathrm{C}_{\mathrm{x}}$ & pH unknown & & & \\
\hline$A_{1}$ & $\begin{array}{l}\text { Small to moderate free-flowing effusion } \\
\qquad(>10 \mathrm{~mm} \text { and }<1 / 2 \text { hemithorax })\end{array}$ & and & $\mathrm{B}_{0}$ & $\begin{array}{l}\text { Negative culture and } \\
\text { Gram stain }\end{array}$ & and & $\mathrm{C}_{0}$ & $\mathrm{pH} \geq 7.20$ & 2 & Low & No \\
\hline \multirow[t]{2}{*}{$\mathrm{A}_{2}$} & \multirow{2}{*}{$\begin{array}{l}\text { Large, free-flowing effusion } \\
(\geq 1 / 2 \text { hemithorax), loculated effusion, } \\
\text { or effusion with thickened } \\
\text { parietal pleura }\end{array}$} & or & $\mathrm{B}_{1}$ & $\begin{array}{l}\text { Positive culture or } \\
\text { Gram stain }\end{array}$ & or & $\mathrm{C}_{1}$ & $\mathrm{pH}<7.20$ & 3 & Moderate & Yes \\
\hline & & & $\mathrm{B}_{2}$ & Pus & & & & 4 & High & Yes \\
\hline
\end{tabular}

Reprinted with permission from Colice GL, Curtis A, Deslauriers J, Heffner J, Light R, Littenberg B, et al. Medical and surgical treatment of parapneumonic effusions: an evidence-based guideline. Chest. 2000;118:1158-71.

model in a stepwise manner. We used propensity-scored matching analysis to adjust several baseline characteristics between the 2 treatment groups. All tests of significance were 2 sided. Odds ratios and $95 \%$ confidence intervals were also calculated.

\section{RESULTS}

\section{Demographic Characteristics}

A total of 111 patients underwent surgical decortication or simple drainage for pleural empyema between January 2008 and July 2011. Patient characteristics are shown in Table 1. The mean patient age was $56.1 \pm 20.0$ years. A total of 88 patients $(79.3 \%)$ were male. The median duration of symptoms to admission was $9.6 \pm 12.0$ days, and the median duration of symptoms to treatment was $13.5 \pm 10.1$ days.

Most empyemas were caused by parapneumonic effusions (73 patients, 65.8\%), but tuberculous empyemas also were common (33 patients, $29.7 \%$ ). Four remaining cases $(3.6 \%)$ resulted from postoperative complication, and 1 case $(0.9 \%)$ was caused by a parasite infection.

A total of 27 of 111 patients $(24.3 \%)$ underwent surgical decortication as the first line of treatment for empyema. In the surgical group, 24 patients $(88.9 \%)$ underwent open surgery, and 3 patients $(11.1 \%)$ underwent VATS. A total of 84 of 111 patients $(75.7 \%)$ were treated with simple drainage; 56 patients $(66.7 \%)$ received a large-bore chest tube, and 28 patients (33.3\%) received a small-bore pigtail catheter.

\section{Clinical Findings and Empyema Severity in Surgical and Simple Drainage Treatment Groups}

There were no significant differences in age, gender, or comorbidity risk factors (including diabetes mellitus) between the surgical group and the drainage group (Table 1). The mean body mass index (BMI) was higher in the surgical group $\left(23.5 \pm 3.2 \mathrm{~kg} / \mathrm{m}^{2}\right.$ vs $21.0 \pm 3.7 \mathrm{~kg} / \mathrm{m}^{2}$, $P=.002$ ), and Eastern Cooperative Oncology Group (ECOG) performance status scores tended to be lower in the surgical group $(P<.001)$. The median Charlson Comorbidity Index (CCI) was higher in the drainage group
(0 [range, $0-3$ ] vs 1 [range, $0-6$ ] in the surgical and drainage groups, respectively; $P=.014)$. The median Acute Physiology and Chronic Health Evaluation II (APACHE II) score at diagnosis also was higher in the drainage group (6 [range, $0-14$ ] vs 9 [range, $0-33$ ] in the surgical and drainage groups, respectively; $P=.013$ ).

There were no significant differences in serum white blood cell counts and serum albumin levels between the 2 treatment groups. The mean erythrocyte sedimentation rate was significantly higher in the surgical group (83.73 $\pm 33.34 \mathrm{~mm} / \mathrm{h}$ vs $67.17 \pm 33.39 \mathrm{~mm} / \mathrm{h}$ in the drainage group; $P=.047$ ), as was serum $\mathrm{C}$-reactive protein $(213.32 \pm 140.28 \mathrm{mg} / \mathrm{L}$ vs $155.18 \pm 113.30 \mathrm{mg} / \mathrm{L}$ in the drainage group; $P=.035$ ) (Table 3 ). The surgical group showed a significantly higher rate of gross pus observed in the pleural fluid $(11 / 14$ cases; $78.6 \%)$ than the drainage group $(35 / 73$ cases, $47.9 \% ; P=.035)$.

Most patients had clinically advanced empyema. Of 111 enrolled patients, $61(55.0 \%)$ were staged as category 3 and $46(41.4 \%)$ were staged as category 4 . There was no significant difference in initial disease severity between the 2 treatment groups $(P=.703$, Table 3$)$.

\section{Subanalysis With Propensity-Scored Matching}

Because several baseline characteristics, including BMI, CCI, ECOG, and APACHE II scores, were significantly different between the surgical and drainage groups, we used propensity-scored matching analysis to investigate whether these factors affected treatment success rate after surgical decortication. After propensity-scored matching, 61 patients were excluded from the analysis and 50 patients ( 20 from the surgical group and 30 from the drainage group) were further analyzed. After matching, the baseline BMI, ECOG, CCI, and APACHE II scores showed no difference between the 2 groups (Table 4 ).

\section{Treatment Outcomes Relative to Treatment Modality}

Of 111 patients, $75(67.6 \%)$ showed treatment success after the first intervention. The surgical group showed a $96.3 \%$ success rate $(26 / 27$ patients), whereas the drainage 
TABLE 3. Radiologic and laboratory findings and severity of pleural empyema

\begin{tabular}{|c|c|c|c|c|}
\hline Variable & Total $(\mathbf{N}=111)$ & Surgery $(n=27)$ & Drainage $(n=84)$ & $P$ value \\
\hline \multicolumn{5}{|l|}{ Laboratory findings } \\
\hline $\mathrm{WBC} / \mathrm{mm}^{2}$ & $12,799.5 \pm 7861.13$ & $13,776.7 \pm 5344.25$ & $12,485.4 \pm 8517.21$ & .460 \\
\hline $\mathrm{ESR}, \mathrm{mm} / \mathrm{h}^{*}$ & $71.3 \pm 33.96$ & $83.7 \pm 33.34$ & $67.2 \pm 33.39$ & .047 \\
\hline $\mathrm{CRP}, \mathrm{mg} / \mathrm{L} \dagger$ & $169.7 \pm 122.52$ & $213.3 \pm 140.28$ & $155.2 \pm 113.30$ & .035 \\
\hline Albumin, g/dL & $3.33 \pm 0.60$ & $3.48 \pm 0.52$ & $3.28 \pm 0.62$ & .143 \\
\hline \multicolumn{5}{|l|}{ Pleural fluid } \\
\hline $\mathrm{pH} \ddagger$ & $7.03 \pm 0.746$ & $7.04 \pm 0.116$ & $7.02 \pm 0.814$ & .934 \\
\hline $\mathrm{WBCs} / \mathrm{mm}^{2} \ddagger$ & $13,247.9 \pm 36,202.03$ & $9801.4 \pm 12,393.83$ & $13,908.9 \pm 39,178.26$ & .700 \\
\hline Glucose, $\mathrm{mg} / \mathrm{dL} \S$ & $89.5 \pm 63.76$ & $103.0 \pm 51.16$ & $86.9 \pm 66.10$ & .492 \\
\hline Gross pus, $\mathrm{n}(\%) \ddagger$ & $46(52.9 \%)$ & $11(78.6 \%)$ & $35(47.9 \%)$ & .035 \\
\hline Category, n (\%)\| & & & & .703 \\
\hline 1 & $1(0.9 \%)$ & $0(0.0 \%)$ & $1(1.2 \%)$ & \\
\hline 2 & $3(2.7 \%)$ & $0(0.0 \%)$ & $3(3.6 \%)$ & \\
\hline 3 & $61(55.0 \%)$ & $16(59.3 \%)$ & $45(53.6 \%)$ & \\
\hline 4 & $46(41.4 \%)$ & $11(40.7 \%)$ & $35(41.7 \%)$ & \\
\hline
\end{tabular}

WBC, ESR, CRP, albumin, $\mathrm{pH}$, and glucose values are all presented as mean units \pm standard deviation. WBC, White blood cell; ESR, erythrocyte sedimentation rate; $C R P$, C-reactive protein. *A total of 88 of 111 cases were examined in this test. $\dagger$ A total of 104 of 111 cases were examined in this test. $\ddagger$ A total of 87 of 111 cases were examined in this test. $\S \mathrm{A}$ total of 55 of 111 cases were examined in this test. \|Categories for poor outcome in patients with parapneumonic effusion. ${ }^{7}$

group showed only a $58.3 \%$ success rate $(49 / 84$ patients) $(P<.001$, Table 5$)$. In 35 drainage group cases with treatment failure, 24 patients were treated with surgical treatment as a next intervention; 2 patients who initially received pigtail catheter drainage were treated with a large-bore chest tube insertion as a follow-up therapy (Table E1). Eleven patients in the drainage group and 1 patient in surgical group who experienced treatment failure died of empyema-attributable causes $(10.8 \%$ of enrolled population; Table 5). The overall survival was $89.2 \%$ (99/ 111 enrolled patients), and survivals were not significantly different between the 2 treatment groups ( $96.3 \%$ vs $86.9 \%$ in the surgical and drainage groups, respectively; $P=.172$; Table 5). There was no significant difference of treatment outcome between organisms. But survival of Gramnegative organisms was lower than of others (Table E2).
Treatment to discharge duration $(10.0 \pm 5.5$ days vs 14.5 \pm 16.0 days in the surgical and drainage groups, respectively, $P=.157)$ and hospitalization duration (13.6 \pm 7.4 days vs $18.5 \pm 19.2$ days in the surgical and drainage groups, respectively; $P=.198$ ) tended to be shorter in the surgical group, although this did not attain statistical significance (Table 5).

After propensity-scored matching analysis, the surgical group showed a significantly greater treatment success rate of $95.0 \%$ (19/20 patients) versus a success rate of $56.7 \%(17 / 30$ patients) in the drainage group $(P=.003$; Table 5). The surgical group also showed a trend of shortened treatment to discharge duration $(9.8 \pm 6.2$ days vs $12.2 \pm 8.5$ days in the drainage group), although this difference was not statistically significant $(P=.272)$. The patients who underwent surgery as a second intervention

TABLE 4. Clinical and laboratory characteristics after propensity-scored matching

\begin{tabular}{|c|c|c|c|c|}
\hline Variables & Total $(\mathbf{N}=\mathbf{5 0})$ & Surgery $(n=20)$ & Drainage $(\mathbf{n}=30)$ & $P$ value \\
\hline Age, y & $49.8 \pm 17.5$ & $53.0 \pm 13.7$ & $47.7 \pm 19.5$ & .300 \\
\hline Gender, male, n (\%) & $40(80.0 \%)$ & $15(75.0 \%)$ & $25(83.3 \%)$ & .470 \\
\hline BMI, $\mathrm{kg} / \mathrm{m}^{2}$ & $23.2 \pm 3.0$ & $23.7 \pm 3.5$ & $22.9 \pm 2.7$ & .362 \\
\hline Diabetes, n (\%) & $11(22.0 \%)$ & $6(30.0 \%)$ & $5(16.7 \%)$ & .265 \\
\hline CCI, median (range) & $0(0-6)$ & $0(0-3)$ & $0(0-6)$ & .611 \\
\hline Mean arterial pressure, $\mathrm{mm} \mathrm{Hg}$ & $86.6 \pm 17.2$ & $87.1 \pm 14.7$ & $86.2 \pm 18.9$ & .864 \\
\hline ECOG, $\mathrm{n}(\%)$ & & & & .841 \\
\hline 0 & $40(80.0 \%)$ & $16(80.0 \%)$ & $24(80.0 \%)$ & \\
\hline 1 & $5(10.0 \%)$ & $2(10.0 \%)$ & $3(10.0 \%)$ & \\
\hline 2 & $4(8.0 \%)$ & $2(10.0 \%)$ & $2(6.7 \%)$ & \\
\hline 3 & $1(2.0 \%)$ & $0(0.0 \%)$ & $1(3.3 \%)$ & \\
\hline APACHE II score at diagnosis, median (range) & $5(0-33)$ & $6(0-11)$ & $5(0-33)$ & .554 \\
\hline Duration of symptoms to admission, $\mathrm{d}$ & $9.9 \pm 8.7$ & $9.6 \pm 9.1$ & $10.1 \pm 8.5$ & .839 \\
\hline Duration of symptoms to treatments, $\mathrm{d}$ & $12.4 \pm 8.5$ & $13.5 \pm 8.9$ & $11.8 \pm 8.3$ & .500 \\
\hline
\end{tabular}

Years, kilograms/meters squared, millimeters of mercury, and days are all presented as mean values \pm standard deviation. $B M I$, Body mass index; $C C I$, Charlson Comorbidity Index; ECOG, Eastern Cooperative Oncology Group; APACHE II, Acute Physiology and Chronic Health Evaluation II. 
TABLE 5. Treatment outcomes according to the treatment modality

\begin{tabular}{|c|c|c|c|c|c|c|c|c|}
\hline \multirow[b]{2}{*}{ Variables } & \multicolumn{4}{|c|}{ All study subjects $(\mathrm{N}=111)$} & \multicolumn{4}{|c|}{ After propensity-scored matching $(\mathbf{N}=\mathbf{5 0})$} \\
\hline & $\begin{array}{c}\text { Total } \\
(\mathbf{N}=\mathbf{1 1 1})\end{array}$ & $\begin{array}{l}\text { Surgery } \\
(\mathbf{n}=27)\end{array}$ & $\begin{array}{c}\text { Drainage } \\
(\mathbf{n}=\mathbf{8 4})\end{array}$ & $P$ value & $\begin{array}{c}\text { Total } \\
(\mathbf{N}=\mathbf{5 0})\end{array}$ & $\begin{array}{l}\text { Surgery } \\
(\mathbf{n}=\mathbf{2 0})\end{array}$ & $\begin{array}{c}\text { Drainage } \\
(\mathbf{n}=\mathbf{3 0})\end{array}$ & $P$ value \\
\hline Treatment success, $\mathrm{n}(\%)$ & $75(67.6 \%)$ & $26(96.3 \%)$ & $49(58.3 \%)$ & $<.001$ & $36(72.0 \%)$ & $19(95.0 \%)$ & $17(56.7 \%)$ & .003 \\
\hline Survival, n (\%) & $99(89.2 \%)$ & $26(96.3 \%)$ & $73(86.9 \%)$ & .172 & $48(96.0 \%)$ & $19(95.0 \%)$ & $29(96.7 \%)$ & .768 \\
\hline Duration of treatment to discharge, $\mathrm{d}$ & $13.4 \pm 14.3$ & $10.0 \pm 5.5$ & $14.5 \pm 16.0$ & .157 & $11.2 \pm 7.7$ & $9.8 \pm 6.2$ & $12.2 \pm 8.5$ & .272 \\
\hline Duration of hospitalization, $\mathrm{d}$ & $17.3 \pm 17.2$ & $13.6 \pm 7.4$ & $18.5 \pm 19.2$ & .198 & $13.8 \pm 8.2$ & $13.6 \pm 8.4$ & $13.9 \pm 8.2$ & .884 \\
\hline
\end{tabular}

Days are presented as mean \pm standard deviation

because of treatment failure of simple drainage showed significantly prolonged hospital stay compared with the patients who underwent surgical decortication as a first intervention (Table E3).

Univariate data analyses are summarized in Table 6. Significant predictors of overall treatment success included an APACHE II score less than $20(P=.008)$, mean arterial pressure $60 \mathrm{~mm} \mathrm{Hg}$ or more $(P=.008)$, serum albumin level $3 \mathrm{~g} / \mathrm{dL}$ or more $(P=.021)$, and surgical decortications as the choice of first intervention $(P<.001)$. Pleural fluid bacterial culture positivity was significantly associated with a poor treatment outcome $(P<.001)$. After propensity-scored matching analysis, only surgical decortications as a choice of the first intervention remained as a significant predictor of treatment success $(P=.003)$, whereas pleural fluid bacterial culture positivity remained a predictor of treatment failure $(P<.001)$.

In a multivariate logistic regression after matching analysis, the strongest predictor of treatment success was surgical decortication as the choice of first intervention (odds ratios of treatment success, $14.53 ; 95 \%$ confidence interval, 1.715-123.074; $P=.014$ ) (Figure 1). Comprehensively, the best predictor of empyema treatment success was the selection of surgical decortication as the first line of treatment.

\section{DISCUSSION}

We showed that selecting surgical decortication as firstline therapy for advanced pleural empyema is an independent and important positive prognostic factor for treatment success. Light ${ }^{8}$ showed that gross pus in pleural fluid, bacterial smear and culture positivity, blood glucose less than $40 \mathrm{mg} / \mathrm{dL}$, pleural effusion $\mathrm{pH}$ less than 7.2, and loculation are the poor prognostic factors in parapneumonic effusion and empyema treatment outcomes. We confirmed that pleural fluid bacterial culture positivity had a significant negative predictive effect on empyema treatment outcome but were unable to verify the importance of the other factors.

The disparity between our findings and those of Light ${ }^{8}$ are possibly because most patients in our study had advanced-stage empyema and already showed gross pleural pus, low pleural fluid $\mathrm{pH}$, and loculation. We categorized patients with parapneumonic effusion by risk for poor outcome, according to evidence-based guidelines established by an expert panel of the ACCP (Table 2). ${ }^{7}$ In our study, $96.7 \%$ of patients were categorized as moderate (category 3 ) or high (category 4) risk for a poor outcome (Table 3).

Surgical decortication was highly successful in treating advanced empyema. In addition, decortication showed a tendency to reduce the treatment to discharge time compared with tube drainage. Wong and colleagues ${ }^{9}$ reported

TABLE 6. Univariate analysis of overall treatment success

\begin{tabular}{|c|c|c|c|c|c|c|}
\hline \multirow[b]{2}{*}{ Variables } & \multicolumn{3}{|c|}{ All study subjects $(\mathrm{N}=111)$} & \multicolumn{3}{|c|}{ After propensity-scored matching $(\mathbf{N}=\mathbf{5 0})$} \\
\hline & Success $(\mathbf{n}=\mathbf{7 5})$ & Failure $(\mathbf{n}=36)$ & $P$ value & Success $(n=36)$ & Failure $(n=14)$ & $P$ value \\
\hline Age, y & $56.1 \pm 19.8$ & $56.1 \pm 20.6$ & .985 & $51.6 \pm 17.9$ & $45.2 \pm 16.1$ & .254 \\
\hline $\mathrm{BMI} \geq 17 \mathrm{~kg} / \mathrm{m}^{2}, \mathrm{n}(\%)$ & $69(92.0 \%)$ & $29(80.6 \%)$ & .079 & $36(100.0 \%)$ & $14(100.0 \%)$ & \\
\hline ECOG, median (range) & $0(0-4)$ & $1(0-4)$ & .061 & $0(0-3)$ & $0(0-2)$ & .821 \\
\hline APACHE II < 20, n (\%) & $72(96.0 \%)$ & $29(80.6 \%)$ & .008 & $34(94.4 \%)$ & $13(92.9 \%)$ & .832 \\
\hline CCI, median (range) & $0(0-6)$ & $1(0-5)$ & .279 & $0(0-6)$ & $0(0-5)$ & .190 \\
\hline Mean blood pressure $\geq 60, \mathrm{n}(\%)$ & $73(97.3 \%)$ & $30(83.3 \%)$ & .008 & $34(94.4 \%)$ & $13(92.9 \%)$ & .832 \\
\hline Serum albumin $\geq 3.0, \mathrm{n}(\%)$ & $56(74.7 \%)$ & $19(52.8 \%)$ & .021 & $32(88.9 \%)$ & $12(85.7 \%)$ & .756 \\
\hline Loculation on CT, n (\%) & $56(74.7 \%)$ & $30(83.3 \%)$ & .306 & $25(69.4 \%)$ & $12(85.7 \%)$ & .303 \\
\hline Pleural fluid $\mathrm{pH} \geq 7.2, \mathrm{n}(\%)$ & $10(18.2 \%)$ & $7(21.9 \%)$ & .675 & $3(11.1 \%)$ & $3(21.4 \%)$ & .375 \\
\hline Pleural fluid glucose, $\mathrm{mg} / \mathrm{dL}$ & $93.7 \pm 62.2$ & $80.9 \pm 67.8$ & .490 & $94.3 \pm 65.3$ & $98.0 \pm 83.7$ & .900 \\
\hline Pleural fluid bacterial smear positivity, n (\%) & $0(0.0 \%)$ & $2(6.3 \%)$ & .061 & $0(0.0 \%)$ & $0(0.0 \%)$ & NS \\
\hline Pleural fluid bacterial culture positivity, n (\%) & $0(0.0 \%)$ & $7(21.9 \%)$ & $<.001$ & $0(0.0 \%)$ & $2(14.3 \%)$ & .044 \\
\hline Decortication as a first treatment, $\mathrm{n}(\%)$ & $26(34.7 \%)$ & $1(2.8 \%)$ & $<.001$ & $19(52.8 \%)$ & $1(7.1 \%)$ & .003 \\
\hline
\end{tabular}

Years and milligrams/deciliter are presented as mean values \pm standard deviation. BMI, Body mass index; ECOG, Eastern Cooperative Oncology Group; APACHE II, Acute Physiology and Chronic Health Evaluation; $C C I$, Charlson Comorbidity Index; $C T$, computed tomography; NS, not significant. 


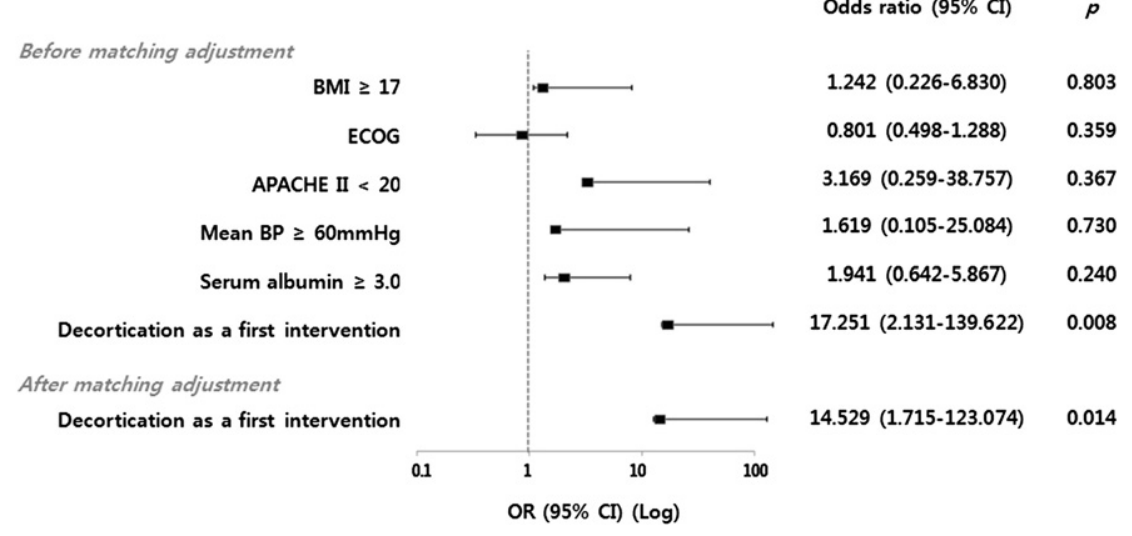

FIGURE 1. Multivariate analysis of overall treatment success. Odds ratios ( $95 \%$ confidence intervals) of overall treatment success with BMI of $17 \mathrm{~kg} / \mathrm{m}^{2}$ or greater, ECOG score, APACHE II score less than 20, mean arterial pressure $60 \mathrm{~mm} \mathrm{Hg}$ or greater, serum albumin $3.0 \mathrm{~g} / \mathrm{dL}$ or greater, and decortications as a first treatment were analyzed using logistic regression in stepwise manner. After propensity-scored matching adjustment, decortication as a first intervention remained the most important predictive factor of a successful treatment outcome. APACHE II, Acute Physiology and Chronic Health Evaluation II; BMI, body mass index; $B P$, blood pressure; $C I$, confidence interval; $E C O G$, Eastern Cooperative Oncology Group; $O R$, odds ratio.

that surgical decortication with VATS significantly reduced hospitalization duration compared with tube drainage treatment in pediatric patients. Thourani and colleagues ${ }^{10}$ reported that surgical decortications reduced the hospital stay compared with simple drainage through a catheter or chest tube. In the last study, surgical decortications also reduced the duration of intensive care unit stay compared with patients treated with simple drainage.

We evaluated a potential role for nutritional status, performance status, and comorbidities assessed with BMI, ECOG, and CCI in affecting empyema treatment outcome. Wozniak and colleagues ${ }^{11}$ reported that using simple drainage as a first treatment compared with surgical intervention was the most powerful prognostic factor for first treatment failure, and that first treatment failure is an important predictive factor of mortality in adult patients with empyema. According to the meta-analysis that followed ACCP guidelines, ${ }^{7}$ surgical treatment for empyema, regardless of whether it was via VATS access or open access, showed a superior success rate when compared with therapeutic thoracocentesis, tube thoracotomy, and fibrinolysis. Also, surgical treatment was superior to simple drainage modalities in reducing total mortality. LeMense and colleagues ${ }^{12}$ suggested using a short trial of closed-chest drainage for 24 to 48 hours after radiologic imaging in patients with empyema, with early aggressive surgical intervention performed in patients who showed no rapid resolution, and reported minimal morbidity and mortality. Likewise, other investigators ${ }^{10,13-15}$ reported that early surgical decortication as a first intervention or after a short trial of simple drainage showed an excellent success rate and minimal mortality in patients with multiloculated effusions and advanced empyema.

In our study, the surgical treatment group showed a more favorable BMI, a better performance status, less comorbidity, and a lower initial APACHE II score compared with the simple drainage treatment group. This suggests that surgeons tend to choose surgical treatment as a first intervention in relatively healthy patients. However, after adjusting the differences of baseline characteristics with propensity-scored matching analysis, multivariate analysis showed that surgical decortication remains favorable for empyema treatment success and patient survival. In our clinical experience, highly debilitated patients are less commonly referred for surgical decortication as a first interventional strategy.

Surgical decortication involves the removal of all fibrous tissue from the pleura and the evacuation of all pus and debris from the pleural space. ${ }^{16}$ Decortication is a major thoracic surgery requiring a large incision and is often difficult to perform in debilitated patients. ${ }^{8}$ However, previous studies showed that decortications did not require long hospitalization stays. According to a study on surgical management of empyema, ${ }^{13}$ the median postoperative stay was reported as only 7 days. In several studies, VATS decortications showed equal or lesser morbidity and mortality compared with open surgery, and the VATS approach also reduced the hospitalization duration. ${ }^{17-19}$

The greater cost of surgical treatment versus simple drainage treatment is often considered to be a disadvantage of this approach, despite its superior success rate in patients with empyema. St Peter and colleagues ${ }^{20}$ reported that VATS decortication did not result in increased treatment success and had a higher cost compared with fibrinolysis in pediatric patients with empyema. However, that study simply compared procedure charge. When considering total treatment costs, it is essential to appreciate that surgical decortication reduces hospitalization duration and rarely requires initiation of additional treatment modalities because of treatment failure. Surgical decortication is not necessarily more expensive than simple drainage intervention. In 
a study that compared cost-effectiveness in adults, ${ }^{10}$ the total hospital charge for surgical decortication was not significantly different compared with the costs for catheter drainage and tube thoracotomy. In fact, surgical decortication resulted in a lower cost compared with the treatment failure group that had undergone catheter drainage or tube thoracotomy.

\section{Study Limitations}

There are several limitations in this study. First, it was a retrospective study, and the study population and clinical setting were selective and limited; thus, selection bias may have occurred. We attempted to adjust for this through the use of propensity score matching, but that did not completely overcome selection bias. Second, tuberculous empyemas were analyzed with nontuberculous empyemas. In our study, 33 patients $(29.7 \%)$ had tuberculous empyema. Tuberculous empyema is a common cause of empyema in intermediate (eg, South Korea) and countries with a high TB burden. Early thoracoscopic intervention showed good outcomes in previous studies. ${ }^{3,21}$ In our study, the outcomes of surgical treatment for tuberculous and nontuberculous empyema were not different.

\section{CONCLUSIONS}

The choice of the first interventional strategy for empyema is critical for treatment success. Even after adjusting for confounding variables, surgical decortication with VATS or thoracotomy is the optimal first line of treatment in patients with advanced empyema.

The authors thank the Medical Research Supporting Section of Yonsei University College of Medicine for statistical support.

\section{References}

1. Light RW. A new classification of parapneumonic effusions and empyema. Chest. 1995;108:299-301.
2. Sharma SK, Mohan A. Extrapulmonary tuberculosis. Indian J Med Res. 2004; 120:316-53.

3. Al-Kattan KM. Management of tuberculous empyema. Eur J Cardiothorac Surg. 2000;17:251-4.

4. Light RW. Parapneumonic effusions and empyema. Clin Chest Med. 1985;6: 55-62.

5. American Thoracic Society. Management of nontuberculous empyema. Am Rev Respir Dis. 1962;85:935-6.

6. Berger HA, Morganroth ML. Immediate drainage is not required for all patients with complicated parapneumonic effusions. Chest. 1990;97:731-5.

7. Colice GL, Curtis A, Deslauriers J, Heffner J, Light R, Littenberg B, et al. Medical and surgical treatment of parapneumonic effusions: an evidence-based guideline. Chest. 2000;118:1158-71.

8. Light RW. Parapneumonic effusions and empyema. Proc Am Thorac Soc. 2006; 3:75-80.

9. Wong KS, Lin TY, Huang YC, Chang LY, Lai SH. Scoring system for empyema thoracis and help in management. Indian J Pediatr. 2005;72:1025-8.

10. Thourani VH, Brady KM, Mansour KA, Miller JI Jr, Lee RB. Evaluation of treatment modalities for thoracic empyema: a cost-effectiveness analysis. Ann Thorac Surg. 1998;66:1121-7.

11. Wozniak CJ, Paull DE, Moezzi JE, Scott RP, Anstadt MP, York VV, et al. Choice of first intervention is related to outcomes in the management of empyema. Ann Thorac Surg. 2009;87:1525-31.

12. LeMense GP, Strange C, Sahn SA. Empyema thoracis. Therapeutic management and outcome. Chest. 1995;107:1532-7.

13. Pothula V, Krellenstein DJ. Early aggressive surgical management of parapneumonic empyemas. Chest. 1994;105:832-6.

14. Ashbaugh DG. Empyema thoracis. Factors influencing morbidity and mortality. Chest. 1991;99:1162-5.

15. Van Way C 3rd, Narrod J, Hopeman A. The role of early limited thoracotomy in the treatment of empyema. J Thorac Cardiovasc Surg. 1988;96:436-9.

16. Thurer RJ. Decortication in thoracic empyema. Indications and surgical technique. Chest Surg Clin N Am. 1996;6:461-90.

17. Angelillo Mackinlay TA, Lyons GA, Chimondeguy DJ, Piedras MA Angaramo G, Emery J. VATS debridement versus thoracotomy in the treatment of loculated postpneumonia empyema. Ann Thorac Surg. 1996;61:1626-30.

18. Chambers A, Routledge T, Dunning J, Scarci M. Is video-assisted thoracoscopic surgical decortication superior to open surgery in the management of adults with primary empyema? Interact Cardiovasc Thorac Surg. 2010;11:171-7.

19. Tong BC, Hanna J, Toloza EM, Onaitis MW, D'Amico TA, Harpole DH, et al Outcomes of video-assisted thoracoscopic decortication. Ann Thorac Surg. 2010;89:220-5.

20. St Peter SD, Tsao K, Spilde TL, Keckler SJ, Harrison C, Jackson MA, et al Thoracoscopic decortication vs tube thoracostomy with fibrinolysis for empyema in children: a prospective, randomized trial. J Pediatr Surg. 2009;44: 106-11.

21. Yim AP. The role of video-assisted thoracoscopic surgery in the management of pulmonary tuberculosis. Chest. 1996;110:829-32. 
TABLE E1. Choice of next treatment modalities and death in patients with treatment failure

\begin{tabular}{lccc}
\hline & \multicolumn{3}{c}{ Treatment failure } \\
\cline { 2 - 4 } \multicolumn{1}{c}{ Variable } & $\begin{array}{c}\text { Total } \\
(\mathbf{N}=\mathbf{3 6})\end{array}$ & $\begin{array}{c}\text { Surgery } \\
(\mathbf{n}=\mathbf{1})\end{array}$ & $\begin{array}{c}\text { Drainage } \\
(\mathbf{n = 3 5})\end{array}$ \\
\hline Next treatment modality & & & \\
$\quad$ Surgical decortications & $24(66.7 \%)$ & $0(0.0 \%)$ & $24(68.6 \%)$ \\
Chest tube drainage & $2(5.6 \%)$ & $0(0.0 \%)$ & $2(5.7 \%)$ \\
No treatment & $10(27.8 \%)$ & $1(100.0 \%)$ & $9(25.7 \%)$ \\
Death & $12(33.3 \%)$ & $1(100.0 \%)$ & $11(31.4 \%)$ \\
\hline
\end{tabular}

All variables are presented as $\mathrm{N}(\%)$.

TABLE E2. Treatment outcomes according to pathogens

\begin{tabular}{|c|c|c|c|}
\hline & $\begin{array}{c}\text { Total } \\
(\mathbf{N}=\mathbf{5 7})\end{array}$ & $\begin{array}{c}\text { Treatment } \\
\text { success } \\
(\mathbf{n}=\mathbf{2 8})\end{array}$ & $\begin{array}{l}\text { Survival } \\
(n=41)\end{array}$ \\
\hline Mycobacterium tuberculosis & $32(56.1 \%)$ & $23(82.1 \%)$ & $32(78.0 \%)$ \\
\hline $\operatorname{Gram}(+)$ & $4(7.0 \%)$ & $1(3.6 \%)$ & $3(7.3 \%)$ \\
\hline Gram (-) & $8(14.0 \%)$ & $2(7.1 \%)$ & $3(7.3 \%)$ \\
\hline Anaerobes & $1(1.8 \%)$ & $1(3.6 \%)$ & $1(2.4 \%)$ \\
\hline Fungus & $12(21.1 \%)$ & $1(3.6 \%)$ & $2(4.9 \%)$ \\
\hline$P$ value & & .068 & .001 \\
\hline
\end{tabular}

Pathogens were isolated in only 57 of 111 patients.
TABLE E3. Outcome of surgical treatment as a first intervention compared with surgical treatment as a second intervention

\begin{tabular}{lccc}
\hline & $\begin{array}{c}\text { Surgery } \\
\text { as a first } \\
\text { intervention } \\
(\mathbf{n}=\mathbf{2 7})\end{array}$ & $\begin{array}{c}\text { Surgery } \\
\text { as a second } \\
\text { intervention } \\
(\mathbf{n}=\mathbf{2 4})\end{array}$ & P value \\
\hline $\begin{array}{l}\text { Survival, n (\%) } \\
\text { Total length of } \\
\text { hospital stay, d }\end{array}$ & $26(96.3 \%)$ & $23(95.8 \%)$ & .932 \\
$\begin{array}{l}\text { The duration of } \\
\text { treatment to } \\
\text { discharge, d }\end{array}$ & $13.56 \pm 7.42$ & $26.83 \pm 23.25$ & .007 \\
\hline Days are presented as mean \pm standard deviation. & & \\
\end{tabular}

